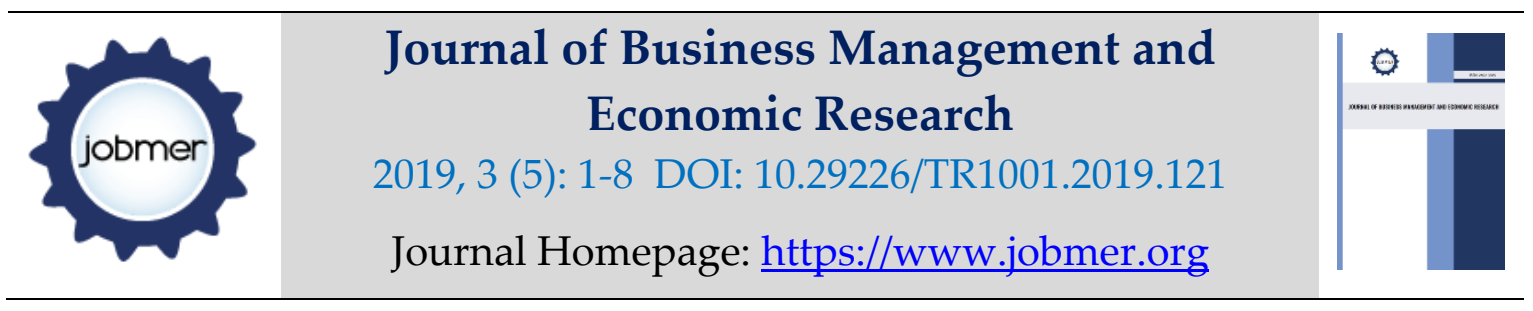

\title{
Research and Promotion of Administrative Procedures for Facilities and Applications for Administrative Agencies in Vietnam
}

\author{
Dr. Nguyen Thi Hang \\ Faculty of Economic Information System, Thai Nguyen University of Information and \\ Communication Technology \\ Email: nthang@ictu.edu.vn
}

\begin{abstract}
For current agencies and organizations in Vietnam, office equipment is one of the fundamental factors playing an important role, ensuring productivity, quality and operational efficiency of office work. . At the same time, the office equipment is an effective arm, helping cadres and civil servants to fulfill their office administrative tasks. Thanks to the application and equipping of machines and equipment for the office, it has contributed to reducing labor force, reducing the burden for office workers. Technical equipment improvements are primarily aimed at stages, such as the word processor table that often goes up to use electronic keyboards, from computer tables to electrical and computer computers for accounting work. Especially since the 70s of the previous century, the stage of document processing has been supported by computers and continuously advanced until now. Computers are indispensable devices in the process of implementing the guaranteed functions. Information security for management activities of a modern office. At the same time, other office equipment thanks to the application of modern scientific and technical achievements that have initiatives and models suitable to each type of work, suitable application for different target groups, Make work performance enhanced. Since then, it will contribute to improving the effectiveness of management workers.
\end{abstract}

Keywords: Office, facilities, office equipment, office administration, office administration. 


\section{The Theoretical Framework for Office Facilities Administration}

Any agency, organization or business that meets the needs of the job, they must equip office equipment to suit their specific characteristics. In the development process of agencies and organizations, the number of equipment is increasingly equipped and improved. Office equipment is one of the important factors to ensure productivity and quality of office work, and is also one of the factors that help cadres and civil servants to fulfill their tasks. Therefore, the management of office equipment is essential. That not only works for work but also improves management efficiency, avoids loss of equipment, is easy to find, search and conduct statistical reports.

Office equipment is the general in general that the machines, tools and spare parts necessary for the operation of the office are the supporting factors or replacing the manual labor of office staff to Help them to get the job done effectively. Office equipment including equipment is assigned to each cadre and civil servant to use (desk, file cabinet, computer, recorder ...) and equipment used for common use in the application taste (copier, shared phone, fax machine ...).

It can be said that thanks to the office equipment, office workers such as typing, writing or enlarging documents, printing, etc. can manage the work smoothly, quickly and promptly. Time, work efficiency is enhanced. Good and adequate office equipment not only helps to facilitate the work but also contributes to maintaining the health of employees working for a long time, the quality of work is guaranteed. Office equipment is one of the important factors that helps individuals perform their tasks well. Because the office staff through the office administrative office has used office equipment to process and provide information quickly, promptly and accurately to improve productivity and work to improve quality. The amount of information provides more information for leaders, while office equipment contributes to reducing the cost of manpower and public with other costs attached.

For the management of office equipment, it is necessary to pay attention to the following basic requirements:

- Office equipment management must be in line with development plans of agencies and units;

The management of office equipment must be specified and detailed from the subject to the management object;

- Office equipment management must be associated with the responsibility of individual managers. This requires the head of the unit to have a specific assignment and arrange and 
transfer office equipment within the unit to suit the needs and job positions. Arranging and assigning people to manage, use and monitor shared office equipment, make books, keep records of equipment delivery records and monitor all equipment office of the unit. For office equipment that no longer needs to be used, it must inform and request the Office (Administration - Administration Department) to transfer or liquidate. To direct the handover of public properties and dossiers of management and use of public properties under their management when there is a change of organization or change of unit heads.

- Office equipment management must meet public requirements, all members of the organization must understand the functions and tasks of the departments and be equipped with equipment suitable for love. the demand and position of the work I undertake, in accordance with the financial conditions and the ability of the units and superiors.

\section{Current Situation of Management of Facilities at Enterprises Today}

Usually, in each agency, to ensure necessary conditions for the implementation of professional jobs, they often equip office equipment such as desks and chairs, computers, printers, file cabinets, electric phone, fax machine, ... Depending on the practical conditions of the unit, the equipment will have investment, replacement and manifest diversity to meet the work needs. Most equipment is used, preserved and managed in a systematic way. However, currently, the management of office equipment in administrative agencies is also carried out by manual method, by books and almost no standardization process has yet been applied yet. achievements of science and technology in the management of office equipment to manage management to achieve science and efficiency.

In units, usually, based on practical needs in office work, the equipment management department has procured, equipped with necessary machines and equipment in the office to serve the public work, general activities of the whole unit.

For the procurement of office equipment: before implementing the procurement of office equipment, the device management department has made specific and detailed plans for the procurement of office equipment. service for general affairs and activities of the company in office work as well as other activities.

The exploitation and use of office equipment of administrative and non-business agencies shall be carried out for the right purposes and strictly according to the State's regulations on asset 
management and use. In the process of using equipment, the company has methods, methods of preserving office equipment that are durable, economical and efficient.

Every year, at the concerned agencies and perform maintenance and maintenance of office equipment on time and promptly repair the damage of equipment to ensure the equipment is preserved. , keep it in the best way.

The process of managing office equipment at the company is still by hand-written method and archival logbook. Thus, the application of measures to manage records is still outdated, the management by this method takes time, effort, costly and not really bring about work efficiency. high. It is no longer relevant to the modernization process of the country, there is no progress along with the development of information technology today.

The process of computerizing the activities of state agencies has been implemented, but until now most agencies have not been able to computerize the process of managing records and documents as required. . Computerization still mainly stops at the exchange of e-mail, drafting of documents and sending and receiving of documents over the network, building a number of databases, exploiting information on the network. Leadership in handling work is mainly on paper documents, so it is necessary to put in place measures to computerize the jobs in the work to solve the task more promptly and quickly.

Application of information technology in administrative agencies in general and businesses in particular is essential, it enhances the positive in state management. We need to come up with solutions to computerize in the management by the application of appropriate information technology to meet the needs of businesses and units that bring results as well. higher workload and catch up with the trend of industrialization modernizing the country along with the development of information technology.

\section{Contents of Office Facilities Management}

Normally, in small and medium enterprises in Vietnam, the management of working equipment consists of three basic contents: the first is managing the process of forming equipment, and the second is managing the equipment. the process of exploiting, using and preserving equipment. Finally, liquidation of equipment that has been fully depreciated.

First of all, for the content of managing equipment formation process. The equipment, after being imported, may be issued or procured and will be managed according to the regulations set by the agency, on the basis of the State regime and the specific operation of the agency. In 
addition, every year the agency also implements additional procurement of equipment derived from actual use needs and that will be done through the unit's annual plan.

After completing the stage of collecting working equipment, the unit will manage the process of exploiting and using equipment. This work includes steps such as assigning equipment to units and individuals responsible for directly managing, exploiting, using and preserving. After that, build and issue rules and regulations on the use of public assets. Form a mechanism of irregular and periodical self-inventory for equipment in the agency, thereby assessing the quantity and quality of equipment. In the process of using and preserving equipment and pans, regularly conducting inspections to detect equipment failures and errors, if any, to handle cases of risks related to equipment. being offices in agencies and organizations.

Finally, the end of the process of using equipment. Equipment that has expired, has depreciated its value or technical innovations, needs to be liquidated. The liquidation of the units' assets must comply with the provisions of law. The agency needs to set up a liquidation committee. Based on the technical characteristics and value of the equipment to choose the appropriate liquidation method, it is possible to choose the auction and public valuation. At the same time, strictly follow the financial management regime of the State.

\section{Propose a Process to Standardize Management for Office Equipment}

Diagram of procurement process and management of office equipment: 


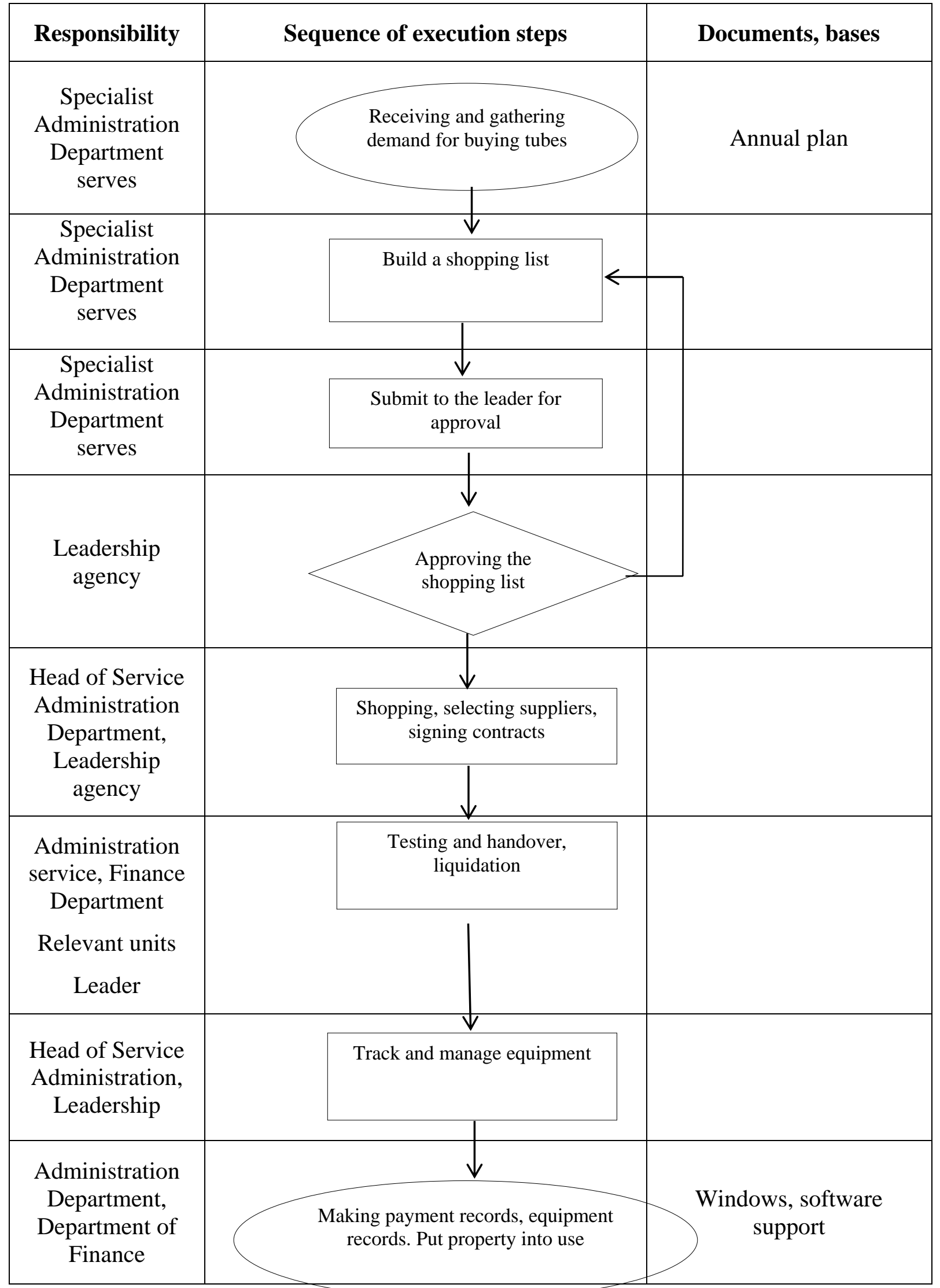




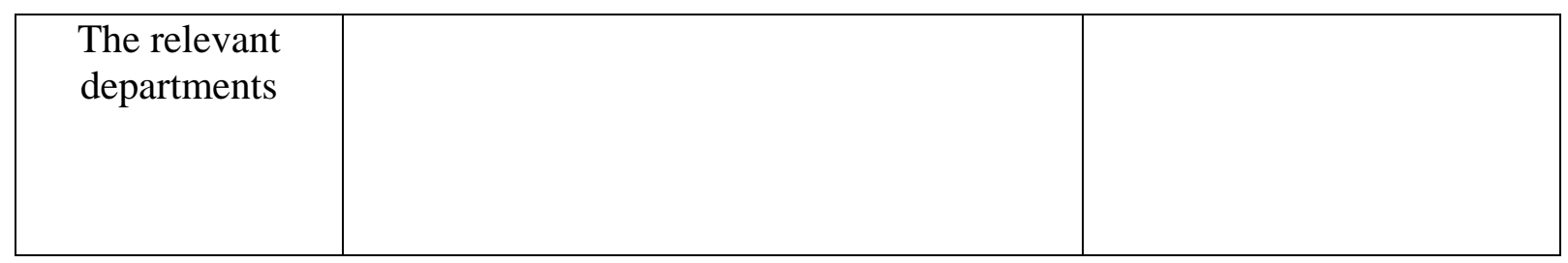

Figure 1. Designing and managing office equipment use procedures

\section{Explain the process}

The process of managing and using office equipment is carried out in the following steps:

Step 1. Receiving the demand for asset procurement: This is done by the Service Manager, based on the annual proposal of the units in the unit. They will then gather and report to the Administration Manager for consideration.

Step 2. Building a shopping list: The Manager of the Administration Department shall coordinate with the Head of the Finance Department based on the assigned budget estimates and the procurement plan to adjust the unit's annual asset procurement list. suitable to the practical situation and specific work needs.

Step 3. Submit to the leader for approval: The Head of Administration Department will submit to the leaders for consideration and approval of the estimated equipment items.

Step 4. Approving the shopping list: The unit leader signs and approves the shopping list.

Step 5. Shopping, selecting suppliers; signing sales contract:

- Based on the list of assets approved by the leaders, according to the unit's plan and the recommendations of the concerned departments. The Head of Administration serves the proposal of procurement, submitting to the leaders for approval.

- After the proposal is approved by the leader; The administrative service department contacted to find quotations of different suppliers of assets intended to buy, in coordination with the Finance Department, to make a minutes to select the supplier.

- Administration Department informs the supplier selected to draft the contract; The contract is checked and signed by the Head of the Finance Department before submitting to the leadership. Based on the signed contract, the Department of Investment and Equipment is responsible for monitoring the implementation of contracts with suppliers, promptly reporting arising problems.

Step 6. Contract acceptance, handover, liquidation:

- Based on the contract and notice of the supplier: the Administration Department serves the organization of checking and taking over the properties and components including: Service Administration Representative, supplier representative, representative unit suffer from property.

- The property handover must ensure the following requirements: full use of the conditions for asset installation; Fully receiving the instructional materials and accessories attached to machines and equipment. The Department of Investment and 
Equipment shall coordinate with the Finance Department in carrying out procedures for warehousing, ex-warehousing and handover of properties to the units for use.

Step 7. Monitoring and management of equipment: Relevant departments conduct the management of units' assets, if any problems arise, they must report back to take appropriate measures.

Step 8. Prepare payment documents, put the assets to use: Administration department to prepare payment documents as prescribed. Asset-using units shall record books for asset tracking at their units.

\section{Conclusion}

Thus, in administrative agencies, the management of office equipment needs to improve and organize the management of equipment in a scientific and effective manner. The management of office equipment is the work to ensure productivity and quality of office work, and is also one of the factors that help cadres and civil servants to fulfill their tasks. , serving management and administration activities of agencies and organizations. The article has deeply explored and proposed the process to re-standardize the facilities management practices for the units, contributing to further improving the work efficiency and management efficiency at the current agencies.

\section{References}

[1]. National Academy of Public Administration, (2011), Curriculum Office, documents and archives in State agencies, Scientific and Technical Publishers.

[2]. Nguyen Huu Tri, (2005), Office Administration, Science and Technology Publishing House.

[3]. Decision No. 170/2006 / QD-TTg promulgating regulations on standards and norms for equipment and working facilities of state agencies and officials, public servants and employees.

[4]. Decision No. 202/2006 / QD-TTg dated August 31, 2006 of the Prime Minister on promulgating regulations on management of state assets at public non-business units.

[5]. Nguyen Huu Than, (2007), Office Administration Administration, Thong Nhat Publishing House.

[6]. Lecturers of the Department of Economic Information Systems, (2018), Lecture on Office Facilities Management, University of Information and Communication Technology. 